\title{
National photonics skills standards for technicians
}

\section{Darrell Hull}

Darrell M. Hull, "National photonics skills standards for technicians," Proc. SPIE 2525, 1995 International Conference on Education in Optics, (13 October 1995); doi: 10.1117/12.224034

SDIE Event: SPIE's 1995 International Symposium on Optical Science, Engineering, and Instrumentation, 1995, San Diego, CA, United States 


\title{
National Photonics Skills Standard for Technicians
}

\author{
Darrell Hull \\ Center for Occupational Research and Development \\ P. O. Box 21689 \\ Waco, Texas 76702-1689
}

\begin{abstract}
$\underline{\text { ABSTRACT }}$
Photonics is defined as the generation, manipulation, transport, detection, and use of light information and energy whose quantum unit is the photon. The range of applications of photonics extends from energy generation to detection to communication and information processing.
\end{abstract}

Photonics is at the heart of today's communication systems, from the laser that generates the digital information transported along a fiber-optic cable to the detector that decodes the information. Whether the transmitted information is a phone call from across the street or across the globe, photonics brings it to you.

Where your health is concerned, photonics allows physicians to do minimally invasive surgery using fiber-optic endoscopes and lasers. Researchers using spectroscopy and microscopy are pushing the frontiers of biotechnology in activities as widespread as diagnosing disease and probing the mysteries of the genetic code.

Advanced sensing and imaging techniques monitor the environment, gathering data on crops and forests, analyzing the ocean's currents and contents, and probing the atmosphere for pollutants. Transportation needs are being impacted by photonic sensors and laser rangefinders that will soon monitor and control the traffic on our nation's highways.

In our factories, photonics provides machine vision systems that give a level of quality control human inspectors could never achieve. In manufacturing, lasers are replacing a variety of cutting, welding, and marking techniques, while imaging systems teamed with neural networks are producing intelligent robots. In short, photonics is paving our way into the new millennium.

The skill standard is intended to define the knowledge and capabilities-the skills-that workers in the photonics industry need. Photonics will be one of the primary battlefields of the world economic conflict, and it is imperative that U.S. photonics technicians be skilled enough to allow the United States to remain competitive in a global marketplace. The focus of this standard is on the skills necessary for employment as a photonics technician and is not intended to be an analysis of those skills that are important for workers in all occupational areas. A comprehensive treatment of the skills necessary for all workers has been the subject of a number of studies, most notably, the work of the Secretary's Commission on the Achievement of Necessary Skills (SCANS). It is our hope at CORD that the work presented in the standard lends more detail and rationale for the accomplishment of the broader skills that should be obtained by all students.

Keywords: Photonics, skills standard, Department of Education, technician, applications, SCANS, curricula, curriculum assessment, worker certification 


\section{THE EVOLUTION OF PHOTONICS TECHNICIANS}

If we trace a trend that started in the early 1970s, the evolution of the role of the photonics technician becomes clear. By 1972, Laser Electro-Optic Technicians (LEOTs) were appreciated if they possessed great troubleshooting skills. As more work was done to develop new processes and applications of lasers, technicians were valued for their ability to understand and use many different types of lasers, and optical and electronic equipment in the laboratory. Today, the applications of lasers and light continue to be developed at much the same rate, and the applications and implementation of these developments have become a large part of what technicians should know-specifically how integrated systems operate. The empirical results of this trend are seen in the changes to LEOT curricula over the last 20 years.

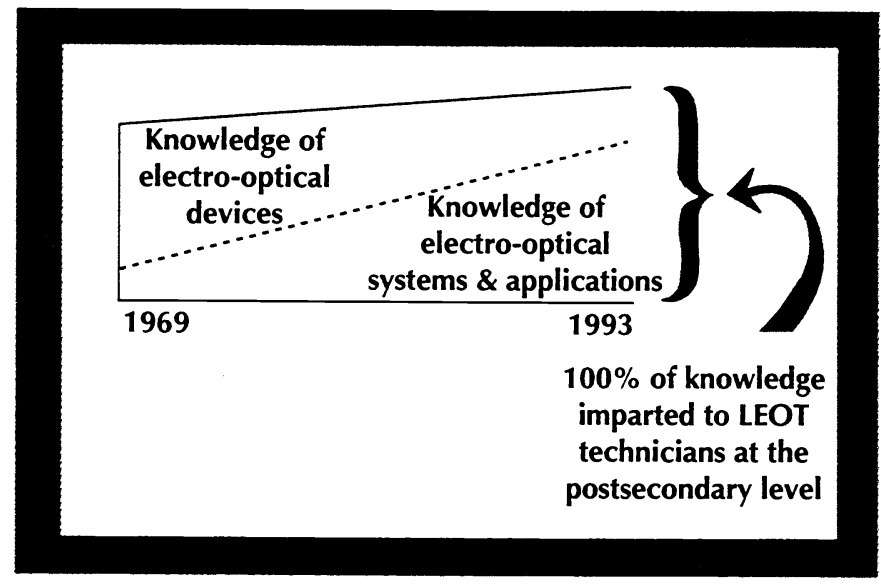

A changing workforce's need for a knowledge of optical and electrical components has evolved into a need for knowledge of whole systems and applications. This means that technicians must better understand the field or industry in which photonics is being used. This is a big change; while technicians have historically been good at assembly/disassembly, troubleshooting, and repair, they have had difficulty adapting, modifying, and interfacing lasers or optics in systems where knowledge of the application is critical.

The number of applications of photonics is so great that no one could be expected to learn all of the skills for each application in just two years of postsecondary education. Thus schools must reorganize their curricula to begin preparing technicians early for many career paths that require an electro mechanical background. Completion of a two-year associate's degree in the photonics field must involve learning not only about the generation, manipulation, transport, and detection of light, but also about systems with integrated technologies. Applications will also have to be studied and/or hands-on skills specific to the field of application must be developed.

How will the hardware of these emerging applications be constructed, tested, maintained and repaired? How will photonics make it from the laboratory to the manufacturing floor to the home or office in a consistent and reliable manner? It will require a team effort. Engineers, physicists and first-line managers cannot support the technology alone; they will need the assistance of certified technicians with a knowledge of photonics and a complement of broad technical skills related to the market. 
The Center for Occupational Research and Development (CORD), a nonprofit, educational, public-service organization, with the support of the U.S. Department of Education, has been given the task of organizing an effort to identify these skills.

\section{DEVELOPMENT PROCESS FOR THE STANDARD}

This National Photonics Skill Standard, an evolving work, ${ }^{1}$ began by defining the field of photonics and then progressed to creating occupational specialties for photonics technicians. As these were determined, a survey was distributed to industry representatives asking them to identify the tools or equipment they or their technicians used and to associate a verb with each tool or piece of equipment. These statements were then called tasks, because they say what a photonics technician does. (Tasks were developed using tools or equipment because, in the photonics industry, technicians do not normally perform a work task unless they have one or more tools or pieces of equipment.)

Industry representatives from each of the following specialty or cluster areas were called together and met in separate groups to validate the task statements with respect to their own group's needs.

The specialty areas are:

- Defense/Public Safety/Aerospace

- Communications

- Medical

- Environmental/Energy/Transportation

- Manufacturing with Photonics/Test and Analysis

- Computers (Entertainment, Consumer Devices, Hard Copy)

The task listings generated by each specialty group were cross-referenced to find the tasks common to all specialty groups. This collection of validated task statements represents the common tasks all photonics technicians should be able to perform.

Finally, educators, primarily from two-year postsecondary institutions but also from secondary schools and four-year universities, participated in translating the task statements into knowledge components. These, then, represent the information a photonics technician must know and understand to be able to perform the tasks. It is expected that these knowledge components will be taught at the postsecondary level.

Additional knowledge components that support these are also provided in the standard. These supporting knowledge components represent only a portion of those that should be taught throughout the secondary experience; they include the necessary elements typically taught in physics, mathematics, biology, and chemistry classes.

\footnotetext{
${ }^{1}$ If you would like to have input into this standard, please contact CORD at (800) 972-2766, or on Internet at http//www.spie.org/photonics_ed.html
} 


\section{SPECIALTY AREAS}

Descriptions of each of the six specialty areas follow, and explain some of the applications of photonics in that area, pointing out the uniqueness of each group and its need for technicians.

\section{Medicine cluster}

Perhaps more than in any other industry, the field of medicine has seen major strides in the commercialization of photonics technology. Laser surgery continues to be effective and has opened the door for photodynamic therapy and fluorescence technology. The desire for minimally invasive techniques makes fiber optics and other photonics components critical development factors for the integration of technology in medicine.

The need for biomedical photonics technicians is a reality, as the scope of knowledge required for this area continues to broaden. The repair and maintenance of machines used in applications like flow cytometry, Deoxyribonucleic Acid (DNA) sequencing, confocal microscopy, and interferometry will eventually become the responsibility of technicians.

\section{Environment/energy/transportation}

Spectrophotometry and laser spectroscopy have already found their way into the burgeoning environmental field. Closer monitoring of pollutants and use of natural energy sources are now a way of life for most power plants and electrical utilities, as well as many oil and gas refineries. Technicians who are comfortable with fieldwork and capable of understanding the effects of harsh environments on optical systems integrated with fluid, electrical, or mechanical stability systems will be important. This seems clear in applications such as solar detoxification of groundwater, laser altimeters for subglacial exploration, ocean-surface spectroscopy, and in providing rural electrification with photovoltaics, which is enjoying renewed interest.

Photonics has an increasingly important role in transportation systems. Presently, photonics-based systems are used for land, air, and sea navigation. The developers and engineers of Intelligent Vehicle Highway Systems will also need photonics technicians who understand vehicle operation, heavy highway construction, or operations research principles for solving traffic-pattern problems.

\section{Defense/public safety/aerospace}

Photonics is critical to defense and aerospace, since devices using photonics are not susceptible to electromagnetic interference like conventional electronics. In addition, defense technology has many applications in the public safety industry. Problems such as drugs, terrorism, border security, urban crime, and natural disasters can in many cases be successfully battled or responded to with photonics-based technology. This requires that the photonics technician understand the operations of Forward Looking Infra-Red (FLIRs), lidar, remote sensing, image processing, and so on, to be able to use these devices to enhance logistics, and command and control issues in a safe and reliable manner.

\section{Computers (entertainment, consumer devices, hard copy)}

The integration of photonics with computer and processing architecture is likely to provide the largest number of opportunities for commercial development. It involves applications like high-speed Optical Character Recognition (OCR), machine vision systems, virtual reality systems, laser light controllers for displays and shows, Compact Disc (CD) players, laser printers, molecular optical switches with photochromic materials, optical neural nets, and so on. High-resolution sensors like Charged Coupled Device (CCD) devices will be widely used in the digitization of artwork, multimedia video, teleconferencing, telepresence, real-time gesture recognition, and digital cinema. 
Matrix displays, including Active-Matrix Liquid Crystal Displays (AMLCDs), Electroluminescent Display (EL) devices, Light Emitting Diodes (LEDs), plasma panels, and field emission displays will gradually supplant Cathode Ray Tubes (CRTs) as the display of choice for direct-view applications. Advances in deformable mirror technology, solid-state lasers, and spatial light modulators will lead to electronic projection systems that rival conventional $35-\mathrm{mm}$ film in both brightness and resolution. Technicians with an understanding of imaging and image processing will become highly valued in the workforce that supports these efforts.

\section{Manufacturing with photonics/test and analysis}

This area concerns those manufacturers who use photonics as part of the manufacturing process, for either fabrication, test, or analysis of their product. The group continues to grow, supported primarily by industrial lasers for cutting, welding, trimming, hole drilling, and heat treating. More and more frequently, the scientific instruments of the laboratory are finding their way onto the floor to perform spectroscopy, or holographic or interferometric testing, or as examination tools in photon microscopy.

\section{Communications}

The "Information Superhighway"-which is actually a photonics superhighway-will create many new jobs for technicians and engineers with skills that relate to fiber optics, lasers, multigigabit processors, networking, and computer engineering. Telephone companies are not the only ones that will require this skilled workforce; television (TV)/cable companies and electric power companies will also be involved in the information-highway revolution. At present, this industry offers the most economic promise for photonics technology, and as a result, it will require that the exit points for students be clearly defined. That way, students will understand the impact of their education upon employment as well as the various possibilities the industry offers.

\section{CURRICULUM CONCERNS}

In defining curricula for photonics technicians, it is important to note that students should decide prior to the 11th grade that they are interested in an electromechanical career pathway. By doing this, they will receive additional applied physics and mathematics, along with vocationally oriented courses in the 11th and 12th grades. These include electronic digital circuits and microprocessors, machining/materials processing, and computer application software. (See Figure 2.)

The students should also have experienced a basic core of applied academic, contextual courses-in mathematics, science, communications, computer literacy, socioeconomics, government/history, languages, arts, and the humanities-in grades 9 through 12. As they move into the freshman and sophomore years at community colleges and technical schools, students with the Tech Prep foundation outlined here will be prepared to understand the knowledge components necessary for the industry-specific tasks. 


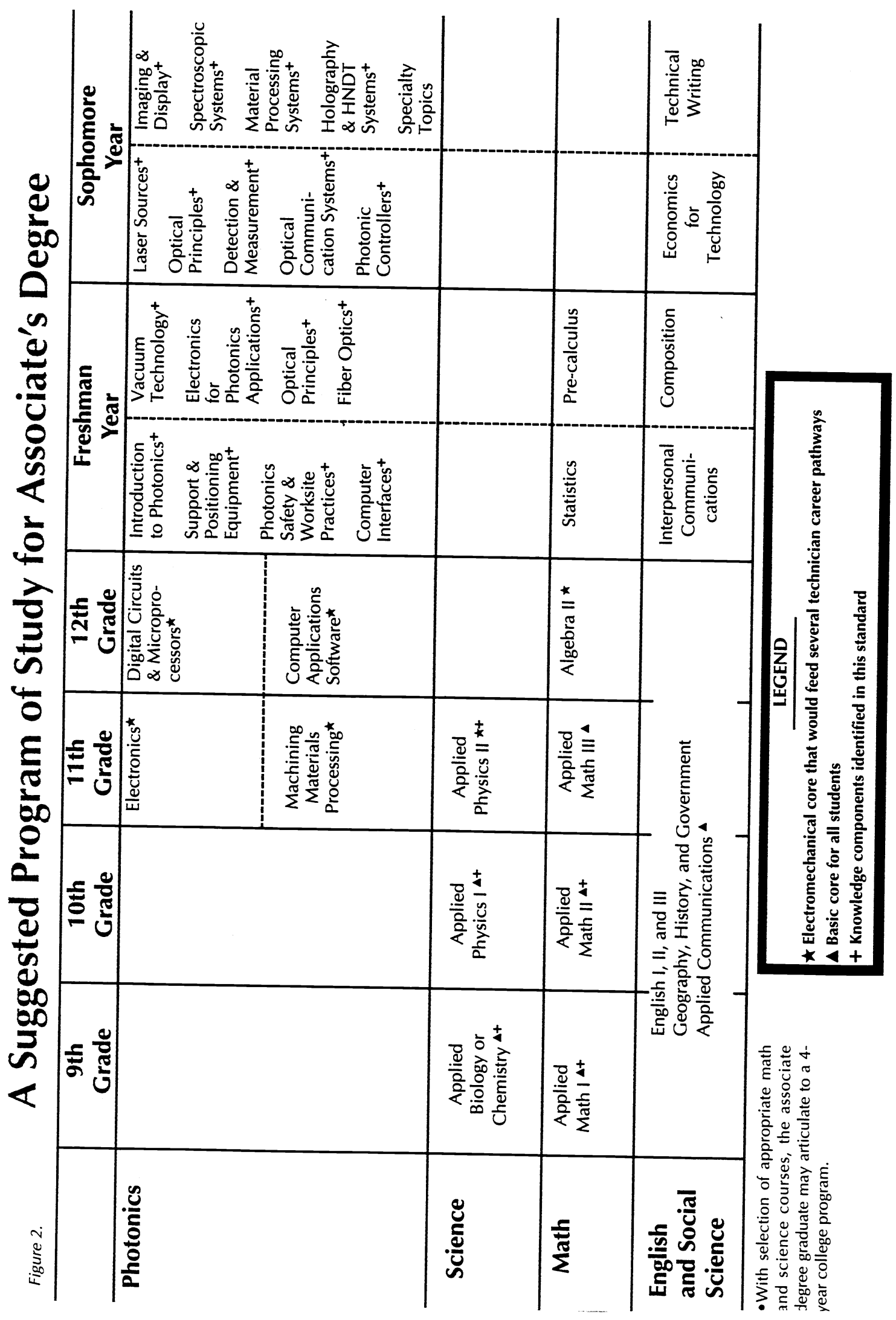

SPIE Vol. $2525 / 543$ 


\section{Photonics technician employment opinion survey}

In a venture separate from the development of National Skills Standards for Photonics Technicians, the Center for Occupational Research and Development conducted an opinion survey of the employment picture in the photonics industry in 1994. Voluntary respondents' survey results revealed:

- At the present time, approximately $345,000^{2}$ photonics technicians are employed in the United States.

- By the year 2000 , approximately $743,000^{3}$ photonics technicians will be needed in the United States.

Respondents to the survey also indicated:

- The most frequently desired education category necessary for employment as a technician was two years of postsecondary technical education (such as an associate degree) or the equivalent. ${ }^{4}$

- Half of the responding companies reported that a small percentage ${ }^{5}$ of their technicians had attended a four-year school.

- The most frequent starting salaries ranged from $\$ 20,000$ to $\$ 25,000$.

Given the tremendous growth in this field and the decreasing numbers of workers trained by the military and filtering into the commercial workforce, community colleges and technical schools will have to work very hard to meet the demand for training and education. These schools cannot meet the demand alone; they will need to work in coordination with secondary schools and four-year institutions to establish sound articulation agreements. It is expected that if they follow this standard in designing curricula and setting up programs, they will provide solid pathways for lifelong learning and good employment possibilities for thousands of our nation's youth.

\footnotetext{
${ }^{2}$ A survey population of 23,640 was used. The survey population was established by selecting supervisors and managers from the mailing list of Photonics Spectra, a leading industry publication. The response rate was $7.2 \%$, considered reasonable for a mail survey that did not offer a reward. Results showed that companies employed a wide range in number of photonics technicians-one reported 500 on staff; however, the mean number was just under 19 (18.85) for companies employing photonics technicians. Of the survey respondents, $77.5 \%$ reported that their company employed at least one photonics technician. Therefore, the estimated total number employed is $77.5 \%$ of the 23,640 companies $x 18.85$, or approximately 345,000 .

${ }^{3}$ Using all of the responses (including those from companies not presently employing photonics technicians), the projected mean number of photonics technicians needed by the year 2000 was 31.426 . Thus the survey projected number is approximately 743,000 [742,910.64=23,640 x 31.426$]$.

${ }^{4} 61$ percent

5 percent
} 